\title{
Strut-and-tie model for externally bonded CFRP-strengthened reinforced concrete deep beams based on particle swarm optimization algorithm: CFRP debonding and rupture
}

\begin{abstract}
A substantial number of studies have been done on the shear strengthening of reinforced concrete (RC) beams with externally bonded carbon fibre reinforced polymers (CFRP). However, in reference to shear, there are still many questions concerning the complexity and nature of the failure mechanism of RC structures strengthened in shear using CFRP. This is particularly true for concrete deep beams because of the nonlinearity of the stress distribution. This study had the goal of developing a simple procedure or model for estimating the shear capacity of RC deep beams strengthened with CFRP sheets. The proposed model was designed based on an extension of the strut-and-tie model (STM) used for un-strengthened $\mathrm{RC}$ deep beams to the case of those shear strengthened with CFRP sheets. The technique avoided the traditional trial-and-error procedure for obtaining the unknown coefficients of the proposed model. It utilized a particle swarm optimization algorithm (PSO), in which the optimal STM of an CFRP-strengthened RC beam was determined by searching for the optimum unknown coefficients (stress distribution and concrete tensile stress reduction factors). This model considered the effects of two CFRP failure modes, namely the CFRP debonding and CFRP tensile rupture failure modes. The proposed model was validated using experimental data collected from the current study and existing literature. The hybrid PSO$\mathrm{STM}$ predicted a mean value $=1.1, \mathrm{SD}=0.098$, and coefficient of variation $(\mathrm{CoV})=8.9 \%$. These results showed that the proposed model has high accuracy and consistency and it can accurately estimate the ultimate shear strength of CFRP-strengthened RC deep beams.
\end{abstract}

Keyword: Strut-and-tie model; Concrete; CFRP; Deep beams; Shear strength; Particle swarm optimization; CFRP debonding and failure modes; MATLAB; ABAQUS 
